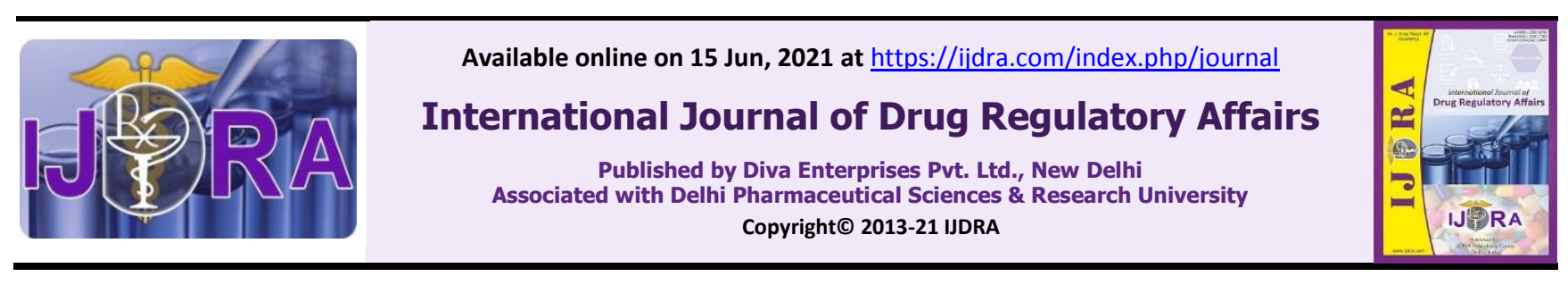

Review Article

Open Occess

\title{
Current regulations for Herbal Medicines in India
}

\author{
Saloni Singh* and Vikesh Kumar Shukla \\ Amity Institute of Pharmacy (AIP), Amity University Noida Sector-126, Uttar Pradesh, India.
}

\begin{abstract}
India is a major source of herbal plants and medicines. There are substantial numbers of plants and herbs which are used as medicines and people prefer them due to fewer side effects. In India, herbal medicines are regulated by AYUSH, CDSCO (Central Drugs Standard Control Organization), AND D\&C Act 1940 \& 1945(amendment). About 8000 herbal medicines have been organized in AYUSH systems in INDIA. This article is about how herbal products are regulated in India.
\end{abstract}

Keywords: AYUSH, Quality Council of India, GCP, D\&C Act, Clinical Trials.

Article Info: Received 26 Apr. 2021; Review Completed 04 Jun. 2021; Accepted 07 Jun. 2021

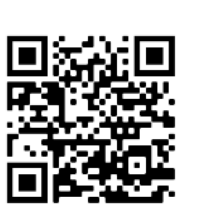

Cite this article as:

Singh S and Shukla VK. Current regulations for Herbal Medicines in India. Int J Drug Reg Affairs [Internet]. 2021 Jun 15 [cited 2021 Jun 15]; 9(2):30-34. Available from:

http://ijdra.com/index.php/journal/article/view/466

DOI: $10.22270 /$ ijdra.v9i2.466

*Corresponding author

\section{Introduction}

There is a worldwide use of herbal medicines. It is medicine obtained completely from plants parts like leaves, roots, stem, flowers, and seeds etc. Herbal medicine, also known as botanical medicine or phytomedicines.

As reported in WHO from total population, 80 percent are currently using herbal drugs for some aspect of primary health care. Herbal medicines are usually considered to be safe and successful agents. Therefore, people prefer more herbal medicines than allopathic, due to less side effects.

In India herbal medicines are used since Vedic age which has been documented in Rig-Veda, and mentioned in Charaka Samhita. Ayurveda, Siddha, homoeopathic system of Medicine and Unani are used as herbal medicine across India. India is the great source of medicinal plants. Forest in India has numerous fragrant and herbal plants which are used for the drug manufacturing. About 8,000 herbal remedies have been organized in AYUSH systems in INDIA. (1)

\section{Herbal Medicines}

Herbal medicines/drugs are plant-derived materials with therapeutic and different health benefits for human, which are acquired or captured from the plants and their parts.

As per WHO definition, there are four group of herbal medicines which are mentioned below: a: Indigenous or Local herbal medicines - This class of herbal drugs are traditionally employed in a local region and people who are local used them for treatment, composition and dose, for longer period of time.

b: Herbal medicine in systems - Drugs under this group is used for a longer period of time and is also documented with their special concepts and theories, and accepted by many countries. Example, Ayurveda, Unani and Siddha.

c: Modified or Changed herbal medicines -In this type herbal drugs are changed in a way like structure, or form including dosage form, dose, mode of administration, methods of preparation and pharmaceutical indications and ingredients. These medicines need to approach the National Regulatory requirements to make the safety as well as efficacy of herbal medicines.

$\mathrm{d}$ : Imported products with an herbal drug base - In this type it all imported herbal drugs (raw materials and products) are mentioned. Imported herbal medicines must be registered and sold in the very same country from where that is originated. Safety and effectiveness data of the medicine should be submitted to the National Authority of the importing country and need to approach the requirements of safety and efficacy of regulation of the herbal medicines within the recipient country. (2)

\section{Indian Regulations}

Herbal drugs represent a main part of all the known system of health in India that is Ayurveda, Yoga, Unani, 
Naturopathy, Siddha and Homeopathy except Allopathy. Central Council of Indian Medicine Act, Research Councils, Department of AYUSH and D\&C Act 1940 (Amendment) all of them regulates herbal medicine in India.

AYUSH department, Indian Council of Medical Research and Council of Scientific and Industrial Research work jointly to achieve the goal of safe and effectual AYUSH products for the recognized diseases and to make new drugs in INDIA.

Herbal drugs comes under Drug and Cosmetics act 1940, and Rules 1945(D \& C ACT). As per rule Ayurvedic, Unani or Siddha drug includes all medicines used for

Table 1. Schedules for Herbal Products in CDSCO internal and external or in the diagnosis of disease, treatment of disease, mitigation or curing the disease or disorder in human beings or animals, and manufactured completely according the formulae described in the valid books of Siddha, the system of Ayurvedic and Unani medicine, given in the very First Schedule.

The D\&C Act extends the control over licensing, formulation composition, manufacture, labelling, packing, quality, and export. Schedule "T" of the act gives us Good Manufacturing Practice (GMP) requirements that is carried for the manufacture of herbal drugs. $(2,3)$

Schedules for Herbal Products in CDSCO (4)

\begin{tabular}{|c|c|c|}
\hline Part of Act / Rule & Chapter / Part & Nature of Activity \\
\hline $\begin{array}{l}\text { Drugs \& Cosmetics } \\
\text { Act } 1940\end{array}$ & $\begin{array}{l}\text { Chapter IV-A (section 33-B } \\
\text { to } 33-\mathrm{N} \text { ) }\end{array}$ & $\begin{array}{l}\text { Provides provisions related to Ayurveda, Siddha and Unani } \\
\text { Drugs }\end{array}$ \\
\hline \multirow[b]{2}{*}{$\begin{array}{l}\text { Drugs \& Cosmetics } \\
\text { Act } 1940 \text { - Schedules }\end{array}$} & The First Schedule & List of scheduled books \\
\hline & The Second Schedule & $\begin{array}{l}\text { Standards to be complied with by imported drugs and by } \\
\text { drugs manufactured for Sale, Stocked or Exhibited for Sale } \\
\text { or Distributed }\end{array}$ \\
\hline \multirow{6}{*}{$\begin{array}{l}\text { Drugs \& Cosmetics } \\
\text { Rules } 1945\end{array}$} & Part XVI (Rule 151-160) & $\begin{array}{l}\text { Manufacture for sale of Ayurvedic (including Siddha) or } \\
\text { Unani Drugs }\end{array}$ \\
\hline & $\begin{array}{l}\text { Part XVI-A (Rule } 160 \text { A - } \\
160 \mathrm{~J})\end{array}$ & $\begin{array}{l}\text { Approval of institutions for carrying out tests on ASU Drugs } \\
\text { and Raw material used in their manufacture }\end{array}$ \\
\hline & Part XVII (Rule 161) & Labeling, Packing and Limit of Alcohol in ASU Drugs \\
\hline & Part XVII (Rule 161-B) & Shelf life and date of expiry for ASU Medicines \\
\hline & Part XVIII (Rule 162-167) & Government analysts and Inspectors for ASU Drugs \\
\hline & Part XIX (Rule 168-170) & Standards of ASU Drugs \\
\hline \multirow{7}{*}{$\begin{array}{l}\text { Drugs \& Cosmetics } \\
\text { Rules } 1945 \text { - Schedules }\end{array}$} & Schedule A & $\begin{array}{l}\text { Different types of forms, particularly } 24 \mathrm{D}, 24 \mathrm{E}, 25 \mathrm{D}, 25 \mathrm{E} \text {, } \\
26 \mathrm{D}, 26 \mathrm{E}, 26 \mathrm{E}-1,47,48,49\end{array}$ \\
\hline & Schedule B-1 & $\begin{array}{l}\text { Fees for the test or analysis by Pharmacopeial Laboratory for } \\
\text { Indian Medicine or the Govt. Analyst }\end{array}$ \\
\hline & Schedule E-1 & $\begin{array}{l}\text { List of poisonous substances under ASU Systems of } \\
\text { Medicine }\end{array}$ \\
\hline & Schedule FF & Standards for Opthalmic Preparations \\
\hline & Schedule T & Good Manufacturing Practices for ASU Medicines \\
\hline & Schedule Y & $\begin{array}{l}\text { Requirements and Guidelines for permission to import and / } \\
\text { or manufacture of new drug for sale and to undertake clinical } \\
\text { trials }\end{array}$ \\
\hline & (Proposed) Schedule Z & $\begin{array}{l}\text { Requirements and Guidelines for permission to manufacture } \\
\text { of ASU Drugs for sale or for clinical trials. }\end{array}$ \\
\hline
\end{tabular}

\section{Ministry of AYUSH (5)}

The Ministry of AYUSH was set-up on 9th November 2014 to make sure the excellent development and propagation of AYUSH systems of health care. Earlier it was known as Department of Indian System of Medicine and Homeopathy (ISM\&H) which was formed in March 1995 and renamed as Department of Naturopathy and Yoga, Ayurvedic, Siddha, Unani, and Homeopathy (AYUSH) on November 2003, that focused attention on development of Education and Research in Naturopathy and Yoga, Ayurvedic , Siddha, Unani and Homeopathy.

\section{Objective of AYUSH}

The main objective is to upgrade the educational standards of Indian System in Medicines and Homoeopathy Universities and college in the country.
To build-up the existing research institutions and make sure a one-time research program on identifiable diseases that these systems have an efficient treatment. To make the plan for promotion, cultivation and regeneration of medicated plants utilized in all the above systems. To develop Pharmacopeial standards for Indian System of Medicines and Homoeopathy drugs.

Objective of AYUSH is to control the drug quality, laying down pharmacopeial standards, overseeing working of pharmacopeial Laboratory of Indian Medicines, by the Quality Council of India and observe the process of Indian Medicine Pharmaceutical Company Limited. AYUSH also controls implementation of Good Manufacturing Practices, setting up of common facilities following Cluster approach and execute the scheme on Drug Quality Control with the disclosure of herbal medical 
formulations, knowledge \& manuscripts, documentation and promotion of regional health traditions.

AYUSH department together with Quality Council of India establish a certification scheme for AYUSH drug products. Always people were concerned for the standards of AYUSH products as regards of their quality, safety and efficacy. To satisfy these concerns a new scheme of voluntary certification of AYUSH products has been started with Quality Council of India.

\section{AYUSH Certification}

The AYUSH certification are done in two levels: (6)

a) AYUSH Standard Mark- based on compliance to the domestic regulatory requirement

b) AYUSH Premium Mark- based on the following options: - Option A: Compliance to GMP Requirement based on WHO Guidelines and levels of contaminant as given in Certification criteria.
Option B: Compliance to regulatory requirement of importing country provided they are stricter than option A above.

\section{Drug Development Process of Herbal Medicines}

The Drug Development Process for herbal drugs in general includes the following details:

- First, synthetic modification and Isolation of bioactive ingredient of it.

- Second, Evaluation of safety and efficacy.

- Third, approval of regulatory for Therapeutic agent in case of new drug.

- $\quad$ Last, Clinical Trials of drugs.

The drug undergoes to drug standardization followed by biological activity, safety studies and preclinical studies, etc. The standardization procedure for various formulations is appended at appropriate places.

1-Identification and Prioritizing the R\&D needs

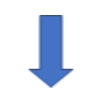

2- Literature Survey

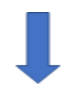

3- Hypothetical Rationale Formulation

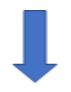

4- Drug development Initiation (Quality Control, Quality Assurance)

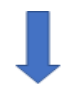

5- Biological activity, Stability studies, pre-clinical studies (With Standard Protocols)

6- Integrated Protocols for Clinical trials development (GCP \& traditional methods)

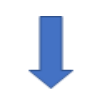

7-Clinical Trials of new drug (With Standard Procedure and approval of Regulatory Authorities)

Figure 1. Drug Development Process Components (7)

\section{Clinical Trials of Herbal Medicines $(8,9)$}

After animal studies of drug, the herbal medicines is studied and tested on human beings as stated by Good Clinical Practice guidelines. The herbal remedies and medicinal plants are to be clinically tested to use in the Allopathic System and later in Allopathic hospitals, the procedures which are laid down by the office of the DCGI for Allopathic drugs needed to be carried forward. This doesn't concern to guidelines issued for clinical trials of Ayurveda, Unani or Siddha drugs by experts in those systems of medicine which can be used later in their own hospitals.

\section{Stages of Clinical Trial}

Phase I studies: Phase 1 trial for herbal medicines is not much necessary because these drugs convey reasonable confidence that they can safely be administered to few carefully monitored clinical subjects in phase II trials. Phase I study usually takes several months.

Phase II studies: In this phase, evaluation of range of dosage in individuals with disease (100-300) is studied. This phase aims for the calculation of appropriate dose ranges or regimens and explains the dose-response relationships in order to give a specific background for the design of large therapeutic trials. Verification of tolerance in this phase is important. Literature review and the provisions in the protocol to be performed, both should focus on full review of the clinical safety parameters. Phase II trial takes long period -from several months to one years and involve up to several hundred 
patients.

Phase III studies: In this phase the trial is done after establishing dose-ranging phase 2 data and involves expended trials of safety and efficacy. This phase involves anywhere from 1000 to 3000 volunteers with the specific disease that are in clinic or hospitals. Patients are closely monitored to decide the effects of the herbal drugs and determine if any adverse effects are involved. This phase of trial confirms that the drug is safe and effective. This phase can take nearly three years.

Many phase $2 \& 3$ studies are randomized, patients are parted into two groups that compare different treatments. One group gets the experimental drug being tested while second gets a placebo. Also, these phase studies are usually 'blinded'-the patients and researchers do not know which patient is getting the experimental or new drug.

Guidelines for Good Clinical Practice for herbal drugs and products in conducting clinical trials in India (9, 10)

The Guidelines for Good Clinical Practice for herbal drugs and products in conducting clinical trials in India which are mentioned below:-

$>$ Herbal medicines and plants which are being used currently should be divulge in literature of a wellrecognized Traditional System of Medicines and are processed in the same manner as given in the literature for Good Manufacturing Practices for making the process as per standard. It is not important to include the phase 1 clinical trial studies. However, it is a necessary part that the substances which is to be tested is present in Indian System of Medicines and are narrated in their texts, the proper need to be examine the toxicity in animals has been reduced or not. Toxicity study is not very important for the phase 2 clinical trial till there is a report present that suggest toxicity or when to use the herbal medicines likely to 3 months or so. It is very important to undergo toxicity study for 4 to 6 weeks in the two species of animals in all these circumstances.

$>$ Herbal medicines clinical trials should be done only after the standardization of the same and to ensure the markers identified for drugs which are being evaluated to be the same always. The informed consent, subjects, inducements for the participation, information to be render to the subject, withdrawing from study and research including children or persons with shortened autonomy, all apply to clinical trials on plant drugs also. These trials must be approved by appropriate scientific and ethical committees of concerned Institutes. However, this is very necessary that plant drugs clinical trial must be carried when someone from Ayurvedic, Siddha, or Unani physician which is a co-investigator in such trial. It would ethically not acceptable or justifiable, of any allopathic physician, carries out clinical trials of the plant without making in knowledge or training in all these systems of medicines. . Hence, a specialist should be present from these systems and the clinical evaluation should be taken jointly.

\section{GCP Guidelines contains (9)}

- Introduction

- Definitions

- Pre-requisites for the study

- Protocol

- Ethical and safety consideration

- Informed consent process

- Compensation for participation

- Responsibilities of sponsor, monitor and investigator

- Data handling

- Record keeping

- Quality assurance

- Statistics

- Special concerns

- Appendix I: guideline for evaluation of ayurvedic, unani and siddha medicine

- Appendix II: ethical issues

- Appendix III: investigator's brochure

- Appendix IV: essential document.

\section{Conclusion}

In India herbal medicines are used in Ayurveda, Siddha, Unani and homoeopathic system of Medicine. Department of AYUSH, ICMR and CSIR work jointly to the safe and effective AYUSH products for the identifiable diseases and to develop new drugs. AYUSH department introduced certification scheme for AYUSH drug products. India develops guideline for conduct clinical trial on herbal medicines, but registration process is not regulated properly. $(11,12)$

\section{Acknowledgements}

We would like to express our sincere gratitude to Dr. Vikesh Kumar Shukla Sir, Faculty of Drug Regulatory Affairs, Amity University, Noida, for his continuous support and guidance.

Financial Disclosure statement: The authors received no specific funding for this work.

\section{Conflict of Interest}

The authors declare that there is no conflict of interest regarding the publication of this article.

\section{References}

1. Chattopadhyay N. Maurya R. Herbal medicines [Internet]. Science Direct; 2015 [cited 2020 Dec 20]. Available from: https://www.sciencedirect.com/topics/agricultural-andbiological-sciences/herbal-medicines

2. Kumar V. Herbal Medicines- Overview on Regulation in India and South Africa [Internet]. India: WJPR; 2017 Jul 24 [cited 2020 Dec 21]. Available from:

https://tinyurl.com/4bbmn5cz

3. Sharma s. Current Status of Herbal products [Internet]. USA: JPBS; 2015 Oct-Dec 07 [cited 2020 Dec 21]. Available from: https://tinyurl.com/4jcsaydn

4. CDSCO, Traditional drugs [Internet]. India: CDSCO; 2020 [cited 2020 Dec 18] Available from: https://cdsco.gov.in/opencms/opencms/en/Home/ 
5. Ministry of Ayush [Internet]. India:AYUSH; 2021 Apr 14 [cited 2020 Dec 18]. Available from:

https://www.ayush.gov.in/

6. Voluntary Certification Scheme for Ayush Products [Internet]. India: Indian Register Quality Systems (IRQS); 2021 [cited 2021 Jan 02]. Available from:

https://www.irqs.co.in/voluntary-certification-scheme-forayush-products/

7. General Guidelines for drug development of Ayurvedic formulations [Internet]. India: Ministry of AYUSH; 2018 [cited 2021 Jan 02]. Available from: https://www.ayush.gov.in/docs/guideline-drugdevelopment.pdf

8. Ramadoss M S K. Koumaravelou K. Regulatory Compliance of Herbal Medicines [Internet]. IJPRS; 2018 Oct 24 [cited 2021 Jan 03]. Available from: https://pharmascope.org/ijrps/article/view/1609/2192

9. Good Clinical Practice Guidelines [Internet]. India: Department of AYUSH; 2013 [cited 2021 Jan 03]. Available from: https://main.ayush.gov.in/sites/default/files/5110899178Final\%20Book\%2028-03-13_0.pdf

10. Srivastava A. Jain R. Agrawal R.K. Ahirwar D. Clinical trials of Herbal Products in India [Internet]. India: RJPT; 2008 [cited 2021 Jan 04]. Available from: https://tinyurl.com/6rp7m2ca

11. Chegu S, Nagabhushanam MV. A Comprehensive Study on Regulation of Herbal Drugs in India, US and European Union. Int J Drug Reg Affairs [Internet]. 2021 Mar 19 [cited 2021 Jun 16];9(1):78-6. Available from: http://ijdra.com/index.php/journal/article/view/458

12. Budhwar V, Yadav S, Choudhary M, Nitesh ,. A Comprehension Study on Regulation Of Herbal Drugs in USA, European Union and India. Int J Drug Reg Affairs [Internet]. 2017 Dec 7 [cited 2021 Jun 16];5(4):8-17. Available from: http://ijdra.com/index.php/journal/article/view/205 